\title{
Exogenous hydrogen sulfide protects H9c2 cardiac cells against high glucose-induced injury by inhibiting the activities of the p38 MAPK and ERK1/2 pathways
}

\author{
WENMING XU ${ }^{1 *}$, WEN WU ${ }^{2 *}$, JINGFU CHEN ${ }^{3}$, RUNMIN GUO $^{3,4}$, JIANCONG LIN $^{1}$, \\ XINXUE LIAO ${ }^{5}$ and JIANQIANG FENG ${ }^{4}$ \\ ${ }^{1}$ Department of Internal Medicine, Huangpu Division of The First Affiliated Hospital, Sun Yat-sen University; \\ ${ }^{2}$ Department of Endocrinology, Guangdong Geriatrics Institute, Guangdong General Hospital, Guangzhou, Guangdong; \\ ${ }^{3}$ Department of Cardiovasology, The Affiliated Hospital, Guangdong Medical College, Zhanjiang, Guangdong; \\ ${ }^{4}$ Department of Physiology, Zhongshan School of Medicine, ${ }^{5}$ Department of Cardiovasology, \\ The First Affiliated Hospital, Sun Yat-sen University, Guangzhou, Guangdong, P.R. China
}

Received May 7, 2013; Accepted July 24, 2013

DOI: $10.3892 /$ ijmm.2013.1462

\begin{abstract}
Hyperglycemia is a risk factor for the development of diabetic cardiovascular complications, which are associated with the activation of the mitogen-activated protein kinase (MAPK) signaling pathway. In this study, we demonstrate the inhibitory effects of exogenous hydrogen sulfide $\left(\mathrm{H}_{2} \mathrm{~S}\right)$ on the activation of the MAPK pathway. The aim of the present study was to determine whether exogenous $\mathrm{H}_{2} \mathrm{~S}$ prevents high glucose (HG)-induced injury by inhibiting the activation of the p38 MAPK and extracellular signal-regulated kinase (ERK)1/2 (members of MAPK) pathways in cardiomyoblasts (H9c2 cells). The findings of the present study demonstrated that the treatment of $\mathrm{H} 9 \mathrm{c} 2$ cells with HG (35 mM glucose) for $24 \mathrm{~h}$ not only significantly induced injury, including cytotoxicity, apoptosis, overproduction of reactive oxygen species (ROS) and the loss of mitochondrial membrane potential (MMP), but also upregulated the expression levels of phosphorylated (p)-p38 MAPK and p-ERK1/2. The increased expression
\end{abstract}

Correspondence to: Dr Jiancong Lin, Department of Internal Medicine, Huangpu Division of The First Affiliated Hospital, Sun Yat-sen University, 183 Huangpu Road E, Guangzhou, Guangdong 510700, P.R. China

E-mail: linjiangcong@163.com

Professor Jianqiang Feng, Department of Physiology, Zhongshan School of Medicine, Sun Yat-sen University, 74 Zhongshan Road 2, Guangzhou, Guangdong 510080, P.R. China

E-mail: fengjq-sums@163.com

*Contributed equally

Key words: hydrogen sulfide, high glucose, H9c2 cell, p38 mitogenactivated protein kinase, extracellular signal-regulated kinase 1/2 levels of p-p38 MAPK and p-ERK1/2 were markedly reduced by pre-treatment of the $\mathrm{H} 9 \mathrm{c} 2$ cells with $400 \mu \mathrm{M}$ sodium hydrogen sulfide (NaHS; a donor of $\mathrm{H}_{2} \mathrm{~S}$ ) prior to exposure to $35 \mathrm{mM}$ glucose. Importantly, pre-treatment of the cells with $400 \mu \mathrm{M}$ NaHS or $3 \mu \mathrm{M}$ SB203580 (a selective inhibitor of p38 MAPK) or $15 \mu \mathrm{M}$ U0126 (a selective inhibitor of ERK1/2) attenuated the HG-induced cardiomyocyte injury, leading to an increase in cell viability and a decrease in the number of apoptotic cells, preventing ROS generation, as well as the loss of MMP. In addition, pre-treatment of the cells with $1,000 \mu \mathrm{M}$ $\mathrm{N}$-acetyl-L-cysteine (a ROS scavenger) prior to exposure to $\mathrm{HG}$ ameliorated the HG-induced cytotoxicity. Taken together, the data from the present study demonstrate for the first time, to our knowledge, that exogenous $\mathrm{H}_{2} \mathrm{~S}$ exerts a protective effect against HG-induced injury by inhibiting the activation of the p38 MAPK and ERK1/2 pathways and preventing oxidative stress in $\mathrm{H} 9 \mathrm{c} 2$ cells.

\section{Introduction}

Diabetic cardiomyopathy is characterized by phenotypic alterations in cardiac muscle, independent of micro- and macrovascular disease, coronary artery disease and hypertension (1-3). Several factors have been reported to be involved in the pathogenesis of this disease, including hyperglycemia, insulin resistance and oxidative stress-induced insults $(3,4,5)$. Among these factors, hyperglycemia is considered one of the most important factors in the onset of diabetic cardiomyopathy $(4,6)$. Thus, studies on the response of cardiac cells to acutely high levels of glucose may provide information for the prevention and treatment of the cumulative effects of high glucose (HG).

It is speculated that most of the effects of excessive glucose are associated with metabolism (7). An increase in glycolysis and hence, pyruvate, enhances the rate of oxidative phosphorylation, which results in reactive oxygen species (ROS) production. The increased ROS production contributes to 
oxidative stress, leading to myocardial damage $(5,8,9)$. For this reason, curcumin, which has antioxidant effects, has been used to prevent diabetic cardiomyopathy in rats with streptozotocin (STZ)-induced diabetes (10). Accumulating evidence suggests that the activation of the mitogen-activated protein kinase (MAPK) signaling pathway attributes to the development of diabetic complications, including cardiac damage (10-13). Mammals express at least 3 distinct groups of MAPKs, including p38 MAPK, extracellular signal-regulated protein kinase 1/2 (ERK1/2) and c-Jun N-terminal kinase (JNK). MAPK signaling pathway is activated by HG stimulation in several types of cell model. Fang et al (14) demonstrated that the exposure of rat mesangial cells to HG (25 mM) significantly upregulated phosphorylated (p) expression levels of $\mathrm{p} 38 \mathrm{MAPK}$ and ERK1/2. The increased expression of p-p38 MAPK and p-ERK1/2 was inhibited by pre-treatment with $\mathrm{N}$-acetyl-L-cysteine (NAC; a ROS scavenger), indicating the involvement of ROS in the HG-induced activation of p38 MAPK and ERK1/2 in rat mesangial cells (14). In STZ-induced diabetic rats, the expression levels of p-p38 MAPK and p-ERK1/2 are enhanced; curcumin has been shown to prevent diabetic cardiomyopathy by inhibiting the activation of p38 MAPK and ERK1/2 (10). Thus, it is reasonable to assume that molecules with antioxidant and inhibitory effects on MAPK activation may protect against HG-induced cardiomyocyte injury. One of these candidate molecules is hydrogen sulfide $\left(\mathrm{H}_{2} \mathrm{~S}\right)$.

$\mathrm{H}_{2} \mathrm{~S}$, a well-known toxic gas with a characteristic smell of rotten eggs, has been qualified as the third gasotransmitter along with nitric oxide (NO) and carbon monoxide (CO) $(15,16) . \mathrm{H}_{2} \mathrm{~S}$ has been considered as an important cardioprotective agent. Exogenous $\mathrm{H}_{2} \mathrm{~S}$ has been shown to reduce myocardial necrosis and rescue contractile activity in isoproterenol-treated rat hearts (17). Chronic $\mathrm{H}_{2} \mathrm{~S}$ therapy improves survival and prevents ischemic-induced heart failure (18). In our previous studies, we demonstrated that exogenous $\mathrm{H}_{2} \mathrm{~S}$ protects $\mathrm{H} 9 \mathrm{c} 2$ cardiac cells against chemical hyoxia-induced injury by inhibiting oxidative stress and upregulating heat shock protein 90 (HSP90) expression $(19,20)$. To date, the role of $\mathrm{H}_{2} \mathrm{~S}$ in diabetes-induced cardiac damage has attracted considerable attention due to to its antioxidant $(9,19-21)$ and modulatory effects on the signaling pathways, including MAPK pathways $(22,23)$. Recently, $\mathrm{H}_{2} \mathrm{~S}$ has been shown to provide protection against cardiomyopathy and vascular dysfunction in models of STZ-induced diabetes (24). In the diabetic db/db mouse heart model, Peake et al (9) demonstrated the protective effects of $\mathrm{H}_{2} \mathrm{~S}$ against ischemic-reperfusion injury by activating nuclear factor (erythroid-derived 2)-like 2 (Nrf2) signaling. However, whether exogenous $\mathrm{H}_{2} \mathrm{~S}$ protects cardiomyocytes against HG-induced injury by inhibiting p38 MAPK and ERK1/2 activation remains unclear. To examine this, in the present study, H9c2 cardiac cells were treated with $35 \mathrm{mM}$ glucose (high glucose, HG) to establish a HG-induced cardiomyocyte injury model. We then focused on i) the effects of HG on the activation of p38 MAPK and ERK1/2; ii) the roles of the activation of p38 MAPK and ERK1/2 in HG-induced cardiomyocyte injury; iii) the effects of exogenous $\mathrm{H}_{2} \mathrm{~S}$ on the HG-induced increase in p38 MAPK and ERK1/2 activation; iv) the roles of p38 MAPK and ERK1/2 activation in the protective effects of exogenous $\mathrm{H}_{2} \mathrm{~S}$ against HG-induced injury in $\mathrm{H} 9 \mathrm{c} 2$ cells. In the current study, to our knowledge, we provide the first evidence that exogenous $\mathrm{H}_{2} \mathrm{~S}$ provides protection against HG-induced injury [including cytotoxicity, apoptosis and the loss of mitochondrial membrane potential (MMP)] by inhibiting the activation of p38 MAPK and ERK1/2 and preventing oxidative stress in $\mathrm{H} 9 \mathrm{c} 2$ cells.

\section{Materials and methods}

Materials. Sodium hydrogen sulfide (NaHS), 2',7'-dichlorofluorescein diacetate (DCFH-DA), Hoechst 33258 and NAC were purchased from Sigma-Aldrich (St. Louis, MO, USA). The Cell Counting Kit-8 (CCK-8) and rhodamine 123 (Rh123) were supplied by Dojindo Laboratories (Kumamoto, Japan). Anti-p-ERK1/2 antibody, anti-ERK1/2 antibody, anti-p38 antibody, anti-p-p38 antibody, U0126 and SB203580 were purchased from Cell Signaling Technology (Boston, MA, USA). Anti- $\beta$-actin antibody, horseradish peroxidase (HRP)conjugated secondary antibody and the BCA Protein Assay kit were obtained from KangChen Bio-tech (Shanghai, China). Fetal bovine serum (FBS) and Dulbecco's modified Eagle's medium (DMEM)-F12 medium were obtained from Gibco BRL (Grand Island, NY, USA). The enhanced chemiluminescence (ECL) solution was purchased from KeyGen Biotech (Nanjing, China). The H9c2 cardiac cells were supplied by the Sun Yat-sen University Experimental Animal Center (Guangzhou, China).

$H 9 c 2$ cell culture and treatments. The H9c2 cardiac cell line was acquired from the Sun Yat-sen University Experimental Animal Center. The cells were cultured in DMEM, supplemented with $10 \%$ FBS in a humidified atmosphere of $95 \%$ air and $5 \% \mathrm{CO}_{2}$ at $37^{\circ} \mathrm{C}$. The culture medium was replaced with fresh medium every 2-3 days and expanded to new culturewares when the cells reached approximately $80 \%$ confluency.

To explore the protective effects of $\mathrm{H}_{2} \mathrm{~S}$ on HG-induced injury, the H9c2 cells were pre-conditioned with $400 \mu \mathrm{M}$ $\mathrm{NaHS}$ for $30 \mathrm{~min}$ prior to exposure to HG for $24 \mathrm{~h}$. To further determine whether the protective effects of NaHS were associated with the inhibition of $\mathrm{p} 38$ MAPK or ERK1/2 activity, the H9c2 cells were pre-conditioned with SB203580 (a selective inhibitor of p38 MAPK), or U0126 (a selective inhibitor of ERK1/2) $60 \mathrm{~min}$ prior to exposure to $35 \mathrm{mmol} / 1$ glucose for $24 \mathrm{~h}$. To confirm whether the protective effects of NaHS were associated with its antioxidant action, $\mathrm{H} 9 \mathrm{c} 2$ cells were pretreated with NAC (a ROS scavenger).

Cell viability assay. The $\mathrm{H} 9 \mathrm{c} 2$ cells in the logarithmic growth phase were cultured in plates at a concentration of $1 \times 10^{4} \mathrm{cells} / \mathrm{ml}$. The CCK-8 assay was then employed to assess the viability of the $\mathrm{H} 9 \mathrm{c} 2$ cardiac cells. After the indicated treatments, the cells were washed with PBS and $10 \mu 1$ CCK-8 solution at a $10 \%$ dilution was added to each well and then the plate was incubated for approximately $90 \mathrm{~min}$ in an incubator. Absorbance at $450 \mathrm{~nm}$ was measured using a microplate reader (Molecular Devices, Sunnyvale, CA, USA). The means of the optical density (OD) of 3 wells in the indicated groups were used to calculate the percentage of cell viability according to the following formula: cell viability $(\%)=\left(\mathrm{OD}_{\text {treatment }}\right.$ 
group $\left./ \mathrm{OD}_{\text {control group }}\right) \times 100 \%$. The experiment was repeated 5 times.

Hoechst 33258 nuclear staining for the assessment of apoptosis. Apoptotic cell death was assessed using the Hoechst 33258 staining method. The H9c2 cells were plated in $35-\mathrm{mm}$ dishes at a density of $1 \times 10^{6}$ cells/well. At the end of the indicated treatments, the cells were harvested and fixed with paraformaldehyde in $0.1 \mathrm{~mol} / 1 \mathrm{PBS}$ for $10 \mathrm{~min}$. After rinsing with PBS, the nuclear DNA was stained with $5 \mathrm{mg} / \mathrm{ml}$ Hoechst 33258 dye for $10 \mathrm{~min}$ before being rinsed briefly with PBS and then visualized under a fluorescence microscope (Bx50-FLA; Olympus, Tokyo, Japan). Viable cells displayed a uniform blue fluorescence throughout the nucleus, whereas apoptotic cells showed fragmented and condensed nuclei. The experiment was repeated 3 times.

Measurement of MMP. MMP was assessed using a fluorescent dye, Rh123, a cell-permeable carionic dye that preferentially enters the mitochondria based on the highly negative MMP. The depolarization of MMP results in the loss of Rh123 from the mitochondria and a decrease in intracellular green fluorescence. H9c2 cardiac cells were cultured on a slide with Eagle's minimal essential medium (EMEM)-F12. After the indicated treatments, the slides were washed 4 times with PBS. The H9c2 cells were incubated with $1 \mathrm{mg} / 1 \mathrm{Rh} 123$ at $37^{\circ} \mathrm{C}$ for $30 \mathrm{~min}$ in an incubator and washed briefly with PBS 4 times. Then Rh123 fluorescence was measured over the entire field of vision using a fluorescence microscope connected to an imaging system (BX50-FLA; Olympus). The mean fluorescence intensity (MFI) of Rh123 from 5 random fields was analyzed using Image J 1.41o software and was taken as an index of the levels of MMP. The experiment was carried out 5 times.

Western blot analysis. After being subjected to the indicated treatments, H9c2 cardiac cells were harvested and lysed with cell lysis solution. Total proteins in the cell lysates were quantified using the BCA Protein Assay kit. Loading buffer was added to the cytosolic extracts and after boiling for approximately $5 \mathrm{~min}$, equal amounts of supernatant from each sample were fractionated by $10 \%$ sodium dodecyl sulphate-polyacrylamide gel electrophoresis (SDS-PAGE). Total proteins in the gel were transferred onto polyvinylidene difluoride (PVDF) membranes. The membranes were blocked for approximately $90 \mathrm{~min}$ at room temperature in fresh blocking buffer $[0.1 \%$ Tween-20 in Tris-buffered saline (TBS-T) containing 5\% milk] and then incubated with either anti-p38 (1:1,000 dilution), anti-p-p38 (1:1,000 dilution), anti-p-ERK1/2 (1:1,000 dilution) or anti-ERK1/2 (1:1,000 dilution) antibodies in freshly prepared TBS-T with 3\% fat-free milk overnight with slow agitation at $4^{\circ} \mathrm{C}$ temperature. Following 3 washes with TBS-T, the membranes were incubated with HRP-conjugated goat anti-rabbit secondary antibody (1:2,500 dilution; KangChen Bio-tech) in TBS-T with 3\% fat-free milk for $90 \mathrm{~min}$ at room temperature. The membranes were washed 3 times with TBS-T solution, developed in ECL solution and visualized using X-ray film. Each experiment was repeated 3 times. For quantification, the films were scanned and analyzed using ImageJ $1.47 \mathrm{i}$ software.

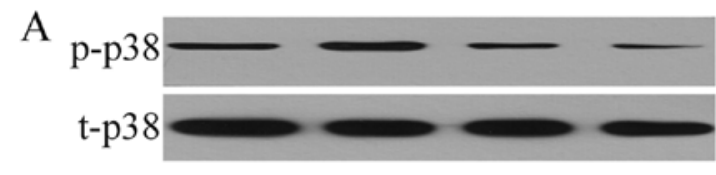

B

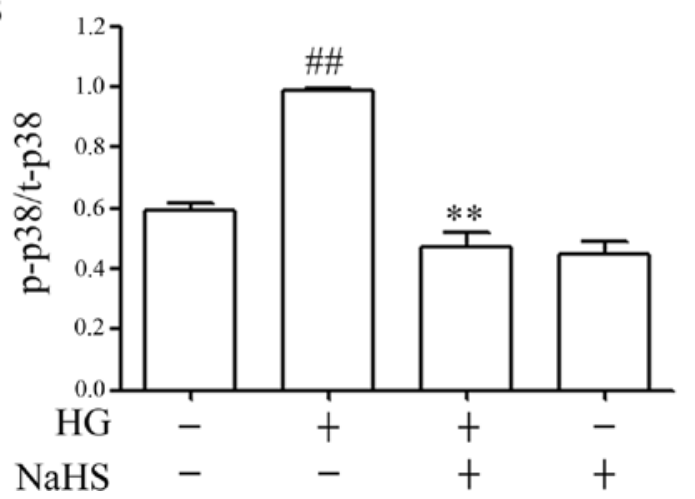

Figure 1. Exogenous hydrogen sulfide $\left(\mathrm{H}_{2} \mathrm{~S}\right)$ reduces the high glucose (HG)-induced increase in the expression of p-p38 mitogen-activated protein kinase (MAPK) in H9c2 cells. H9c2 cells (pre-treated or not with $400 \mu \mathrm{M}$ NaHS for $30 \mathrm{~min}$ ) were treated with $35 \mathrm{mM}$ glucose for $24 \mathrm{~h}$. (A) The expression of phosphorylated (p)-p38 MAPK was measured by western blot analysis and (B) quantified by densitometric analysis of the data in (A) using Image J 1.410 software. Data are shown as the means $\pm \mathrm{SE}(\mathrm{n}=3) .{ }^{\# \#} \mathrm{P}<0.01$ vs. the control; ${ }^{* *} \mathrm{P}<0.01$ vs. the HG group. t, total.

Measurement of intracellular ROS levels. The determination of intracellular ROS levels was performed by measuring a fluorescent product formed by the oxidation of DCFH-DA. Briefly, the culture medium was removed and the cells were washed with PBS 3 times. Following the addition of fresh culture medium, the cells were incubated with DCFH-DA at the final concentration of $10 \mu \mathrm{mol} / 1$ for $30 \mathrm{~min}$ at $37^{\circ} \mathrm{C}$. The cells were then washed again with PBS 3 times and the relative amount of fluorescent product was assessed using a fluorescence microscope connected to an imaging system (BX50-FLA; Olympus). The MFI from 5 random fields was measured using ImageJ 1.410 software and the MFI was used as an index of the amount of ROS. The experiment was carried out 5 times.

Statistical analysis. All data are presented as the means \pm SEM. Differences between groups were analyzed one-way analysis of variance (ANOVA) using SPSS 13.0 software (SPSS, Chicago, IL, USA) followed by the LSD post hoc comparison test. A P-value $<0.05$ was considered to indicate a statistically significant difference.

\section{Results}

Exogenous $\mathrm{H}_{2} \mathrm{~S}$ inhibits the $\mathrm{HG}$-induced upregulation of the expression of p-p38 MAPK in H9c2 cells. As illustrated in Fig. 1, treatment of the $\mathrm{H} 9 \mathrm{c} 2$ cells with $35 \mathrm{mM}$ glucose (HG) for $24 \mathrm{~h}$ significantly upregulated the expression of p-p38 MAPK in the H9c2 cells. However, this increase in the expression of p-p38 MAPK was attenuated by pre-treatment of the cells with $400 \mu \mathrm{M}$ NaHS (a donor of $\mathrm{H}_{2} \mathrm{~S}$ ) for $30 \mathrm{~min}$ prior to exposure to HG. NaHS at $400 \mu \mathrm{M}$ alone did not alter the basal expression of p-p38 MAPK in the H9c2 cells (Fig. 1). 


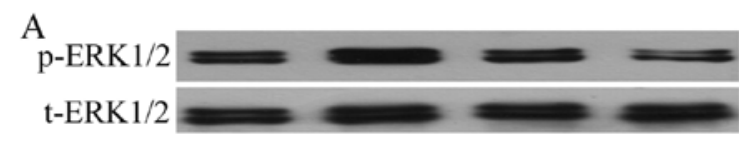

B

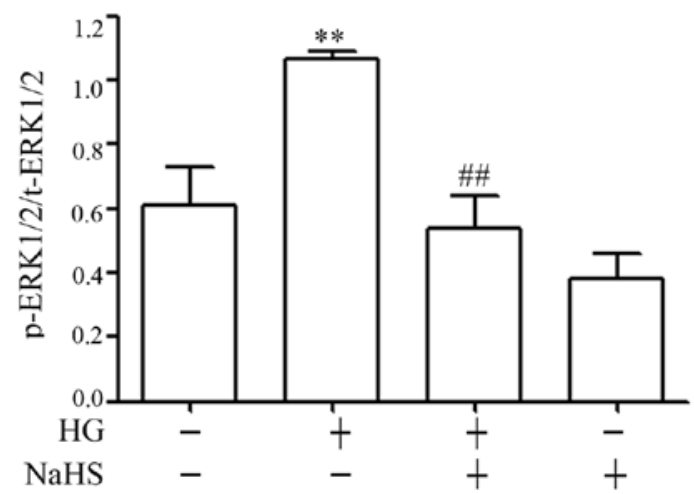

Figure 2. Exogenous hydrogen sulfide $\left(\mathrm{H}_{2} \mathrm{~S}\right)$ suppresses the high glucose (HG)-induced activation of extracellular regulated-signal kinase (ERK) $1 / 2$ in H9c2 cells. H9c2 cells (pre-treated or not with $400 \mu \mathrm{M} \mathrm{NaHS}$ for $30 \mathrm{~min}$ ) were treated with $35 \mathrm{mM}$ glucose (HG) for $24 \mathrm{~h}$. (A) The expression of ERK1/2 was assessed by western blot analysis and (B) quantified by densitometric analysis using ImageJ 1.41o software. Data are presented as the means \pm SE $(n=3)$. ${ }^{\# \#} \mathrm{P}<0.01$ vs. the control group; ${ }^{* *} \mathrm{P}<0.01$ vs. HG treatment group. $\mathrm{t}$, total.

Exogenous $\mathrm{H}_{2} \mathrm{~S}$ attenuates the $\mathrm{HG}$-induced increase in the expression of $p-E R K 1 / 2$ in $H 9 c 2$ cells. The results from western blot analysis revealed that the exposure of H9c2 cells to $35 \mathrm{mM}$ glucose for $24 \mathrm{~h}$ markedly elevated the expression levels of p-ERK1/2 (Fig. 2), but did not induce significant changes in the expression of total (t)-ERK1/2. Additionally, similar to the inhibitory effects of NaHS on p-p38 MAPK expression, pre-treatment of the $\mathrm{H} 9 \mathrm{c} 2$ cells with $400 \mu \mathrm{M}$ NaHS for $30 \mathrm{~min}$ prior to exposure to $35 \mathrm{mM}$ glucose markedly reduced the increased expression of p-ERK1/2 induced by HG for $24 \mathrm{~h}$ (Fig. 2). Alone, NaHS at $400 \mu \mathrm{M}$ did not alter the basal expression of p-ERK1/2 in the H9c2 cells.

NaHS, p38 MAPK inhibitor and ERK1/2 inhibitor ameliorate HG-induced cytotoxicity in $\mathrm{H} 9 \mathrm{c} 2$ cells. Firstly, we examined whether exogenous $\mathrm{H}_{2} \mathrm{~S}$ protects $\mathrm{H} 9 \mathrm{c} 2$ cells against HG-induced cytotoxicity. The H9c2 cells were pre-treated with $400 \mu \mathrm{M}$ NaHS for $30 \mathrm{~min}$ followed by exposure to $35 \mathrm{mM}$ glucose for $24 \mathrm{~h}$. Our results revealed that pre-treatment with NaHS for 30 min significantly decreased HG-induced cytotoxicity, as evidenced by an increase in cell viability (Fig. 3). Since the above results (Figs. 1 and 2) showed that the expression levels of p-p38 MAPK and p-ERK1/2 were enhanced by HG treatment, we then wished to confirm whether p-p38 MAPK and p-ERK1/2 activation contributed to HG-induced cytotoxicity. As shown in Fig. 3, pre-treatment of the H9c2 cells with either $3 \mu \mathrm{M} \mathrm{SB} 203580$ (an inhibitor of p38 MAPK) or U0126 (a selective inhibitor of ERK1/2) for 60 min prior to exposure to $35 \mathrm{mM}$ glucose markedly suppressed HG-induced cytotoxicity, leading to an increase in cell viability. These findings suggest that the activation of p38 MAPK and ERK1/2 is involved in HG-induced cytotoxicity.

NaHS, p38 MAPK inhibitor and ERK1/2 inhibitor diminish $H G$-induced apoptosis of $H 9 c 2$ cells. We further explored the

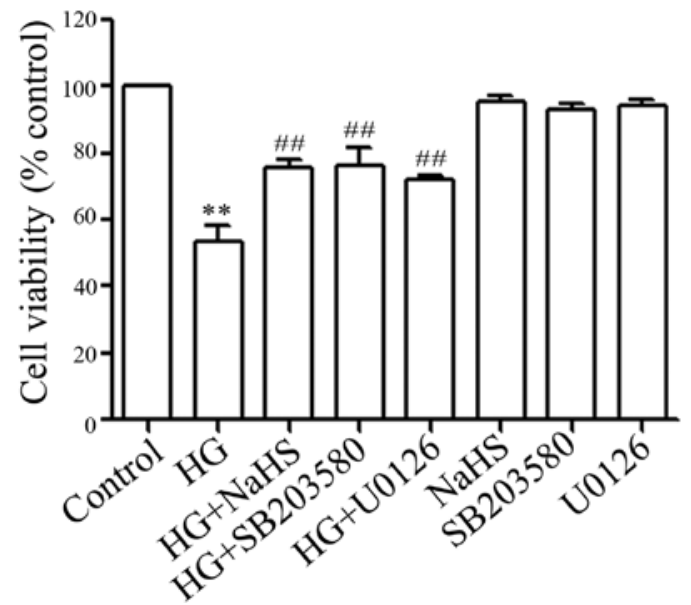

Figure 3. Exogenous hydrogen sulfide $\left(\mathrm{H}_{2} \mathrm{~S}\right)$ p38 mitogen-activated protein kinase (MAPK) inhibitor and extracellular regulated-signal kinase (ERK)1/2 inhibitor protect $\mathrm{H} 9 \mathrm{c} 2$ cells against high glucose (HG)-induced cytotoxicity. H9c2 cells (pre-treated or not with $400 \mu \mathrm{M} \mathrm{NaHS}$ for $30 \mathrm{~min}$ or $3 \mu \mathrm{M}$ SB203580 or $15 \mu \mathrm{M}$ U0126 for $60 \mathrm{~min}$ ) were treated with $35 \mathrm{mM}$ glucose for $24 \mathrm{~h}$. Cell viability was assessed using the CCK- 8 assay. Data are shown as the means $\pm \mathrm{SE}(\mathrm{n}=3) .{ }^{* *} \mathrm{P}<0.01$ vs. the control group; ${ }^{\# \#} \mathrm{P}<0.01$ vs. the $\mathrm{HG}$ treatment group.

effects of exogenous $\mathrm{H}_{2} \mathrm{~S}$, p38 MAPK inhibitor and ERK1/2 inhibitor on HG-induced apoptosis. As shown in Fig. 4B, the exposure of the H9c2 cells to $35 \mathrm{mM}$ glucose for $24 \mathrm{~h}$ induced characteristics typical of apoptosis, as evidenced by tbe condensation of chromatin, the shrinkage of nuclei and apoptotic bodies. Of note, pre-treatment of the cells with $400 \mu \mathrm{M}$ NaHS for 30 min prior to HG exposure significantly attenuated the HG-induced increase in the number of cells with nuclear condensation and fragmentation (Fig. 4C). Similarly, pretreatment of the cells with either $3 \mu \mathrm{M}$ SB203580 or $15 \mu \mathrm{M}$ U0126 for 60 min prior to HG treatment inhibited HG-induced apoptosis (Fig. 4D and E). Alone, NaHS, SB203580 or U0126 did not significantly affect cell morphology or the percentage of apoptotic H9c2 cells (Fig. 4F-H). The above results indicate that exogenous $\mathrm{H}_{2} \mathrm{~S}$ protects $\mathrm{H} 9 \mathrm{c} 2$ cells against HG-induced apoptosis which is associated, at least in part, with the activation of p38 MAPK and ERK1/2.

NaHS, p38 MAPK inhibitor and ERK1/2 inhibitor reduce $H G$-triggered oxidative stress in $H 9 c 2$ cells. Accumulating evidence has indicated that the generation of ROS participates in HG-induced cardiac injury (25). Therefore, in this study, we observed the effects of exogenous $\mathrm{H}_{2} \mathrm{~S}$ on HG-induced ROS generation in $\mathrm{H} 9 \mathrm{c} 2$ cells. It was shown that treatment of the cells with $35 \mathrm{mM}$ glucose for $24 \mathrm{~h}$ considerably increased the generation of ROS (Fig. 5B). The increased ROS generation was diminished by pre-treatment of the cells with $400 \mu \mathrm{M}$ NaHS for 30 min prior to exposure to HG (Fig. 5C), illustrating the inhibitory effects of exogenous $\mathrm{H}_{2} \mathrm{~S}$ on $\mathrm{HG}$-induced oxidative stress. To investigate whether the activation of p38 MAPK and ERK1/2 is involved in HG-induced oxidative stress, the H9c2 cells were pre-treated with $3 \mu \mathrm{M} \mathrm{SB} 203580$ or $15 \mu \mathrm{M}$ U0126 for $60 \mathrm{~min}$ prior to exposure to HG. As shown in Fig. 5 , pre-treatment with SB203580 (Fig. 5D) or U0126 (Fig. 5E) markedly reduced the HG-induced increase in ROS genera- 

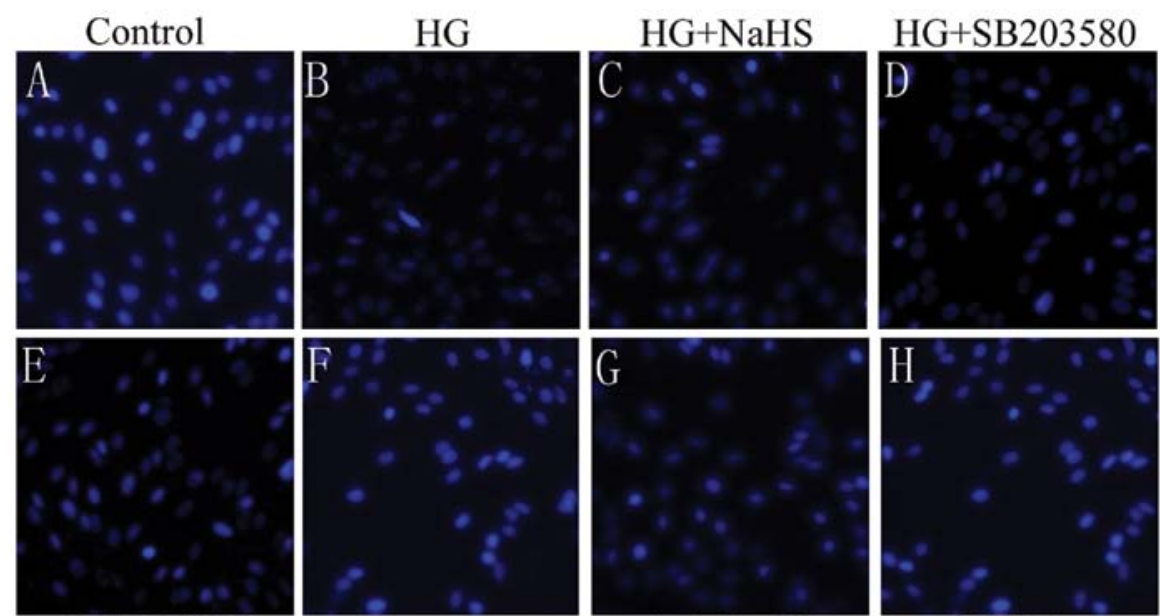

HG+U0126

NaHS

SB203580

U0126

I

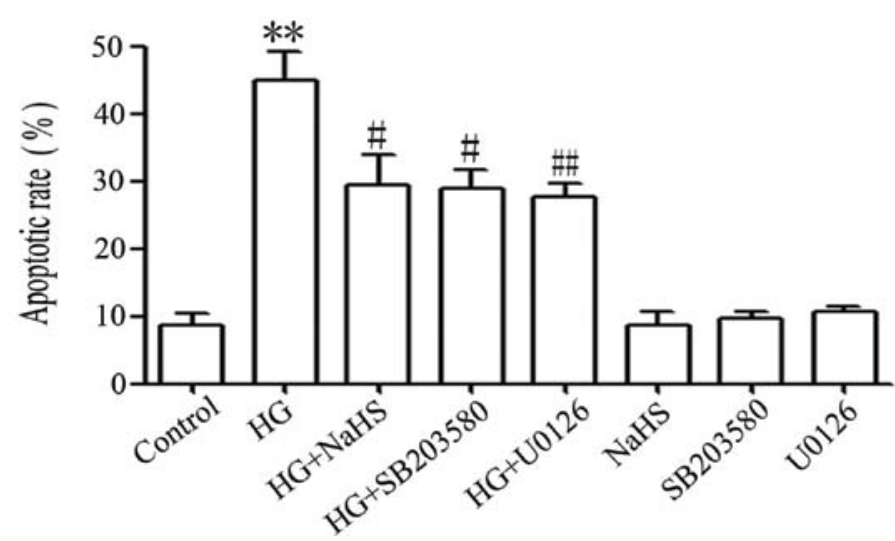

Figure 4. Exogenous hydrogen sulfide $\left(\mathrm{H}_{2} \mathrm{~S}\right)$, p38 mitogen-activated protein kinase (MAPK) inhibitor and extracellular regulated-signal kinase (ERK)1/2 inhibitor suppress high glucose (HG)-induced apoptosis in $\mathrm{H} 9 \mathrm{c} 2$ cells. (A-H) Hoechst 33258 nuclear staining followed by fluorescence imaging was used to detect cell apoptosis. (A) Control group; H9c2 cells were (B) treated with $35 \mathrm{mM}$ glucose for $24 \mathrm{~h}$; (C) pre-treated with $400 \mu \mathrm{M}$ NaHS for $30 \mathrm{~min}$ prior to exposure to $35 \mathrm{mM}$ glucose for $24 \mathrm{~h}$; (D) treated with $3 \mu \mathrm{M} \mathrm{SB} 203580$ for $60 \mathrm{~min}$ followed by exposure to $35 \mathrm{mM}$ glucose for $24 \mathrm{~h}$; (E) treated with $15 \mu \mathrm{M}$ U0126 for $60 \mathrm{~min}$ followed by exposure to $35 \mathrm{mM}$ glucose for $24 \mathrm{~h}$; (F) treated with $400 \mu \mathrm{M} \mathrm{NaHS}$ for $30 \mathrm{~min}$ followed by $24 \mathrm{~h}$ of culture; (G) treated with $3 \mu \mathrm{M}$ SB203580 for $60 \mathrm{~min}$ followed by $24 \mathrm{~h}$ of culture; (H) treated with $15 \mu \mathrm{M} \mathrm{U} 0126$ for $60 \mathrm{~min}$ followed by $24 \mathrm{~h}$ of culture; (I) The apoptotic rate was analyzed

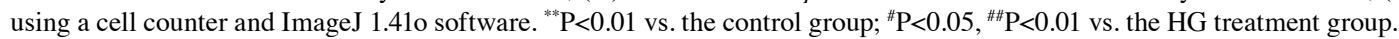

tion, suggesting that the activation of p38 MAPK and ERK1/2 contributes to the overproduction of ROS induced by HG.

NaHS, p38 MAPK inhibitor and ERK1/2 inhibitor suppress the $H G$-induced dissipation of MMP in H9c2 cells. Previous studies have shown that ROS induces mitochondrial damage, which has been implicated in HG-induced cardiac insults (25). Thus, we explored whether exogenous $\mathrm{H}_{2} \mathrm{~S}$ prevents the loss of MMP in HG-treated H9c2 cells. As shown in Fig. 6, treatment of the cells with $35 \mathrm{mM}$ glucose for $24 \mathrm{~h}$ markedly induced mitochondrial damage, as evidenced by the dissipation of MMP (Fig. 6B). Importantly, the dissipation of MMP was ameliorated by pre-conditioning with $400 \mu \mathrm{M}$ NaHS for 30 min prior to treatment of the cells with $35 \mathrm{mM}$ glucose (Fig. 6C and I), suggesting the protective effects of exogenous $\mathrm{H}_{2} \mathrm{~S}$ against the HG-induced loss of MMP. In addition, pretreatment of the cells with either $3 \mu \mathrm{M} \mathrm{SB} 203580$ (Fig. 6D) or $15 \mu \mathrm{M} \mathrm{U} 0126$ (Fig. 6E) for $60 \mathrm{~min}$ prior to exposure to $35 \mathrm{mM}$ glucose antagonized the HG-induced dissipation of MMP, indicating the involvement of the activation of p38 MAPK and ERK1/2 in HG-induced mitochondrial insults in H9c2 cells.
Alone, NaHS at $400 \mu \mathrm{M}$ or $3 \mu \mathrm{M} \mathrm{SB} 203580$ or $15 \mu \mathrm{M} \mathrm{U} 0126$ did not induce the loss of MMP (Fig. 6F-I).

ROS scavenger decreases the HG-induced cytotoxicity in $H 9 c 2$ cells. In order to demonstrate whether the role of exogenous $\mathrm{H}_{2} \mathrm{~S}$ (NaHS) in inhibiting HG-induced cytotoxicity is associated with its antioxidant effects, the $\mathrm{H} 9 \mathrm{c} 2$ cells were pre-treated with 1,000 $\mu \mathrm{M}$ NAC (a ROS scavenger) for $60 \mathrm{~min}$ prior to esposure to $35 \mathrm{mM}$ glucose for $24 \mathrm{~h}$. Similar to the inhibitory effects of NaHS pre-treatment on HG-induced cytotoxicity, NAC pre-treatment significantly inhibited $\mathrm{HG}$-induced cytotoxicity, resulting in an increase in cell viability (Fig. 7), revealing that the antioxidant effects of $\mathrm{H}_{2} \mathrm{~S}$ contribute, at least in part, to the inhibitory effects of exogenous $\mathrm{H}_{2} \mathrm{~S}$ on cytotoxicity induced by $\mathrm{HG}$ in the $\mathrm{H} 9 \mathrm{c} 2$ cells.

\section{Discussion}

Increasing clinical studies have shown that hyperglycemia is a risk factor for the development of diabetic cardiomyopathy. However, the mechanisms responsible for HG-induced cardiac 


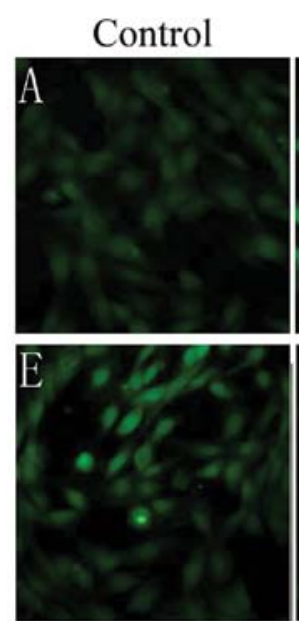

$\mathrm{HG}+\mathrm{U} 0126$
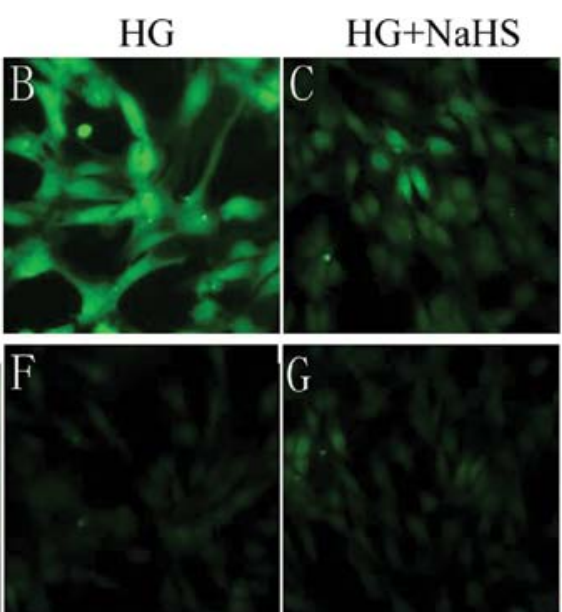

$\mathrm{NaHS}$

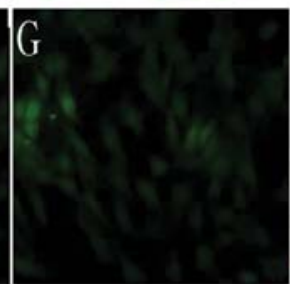

SB203580
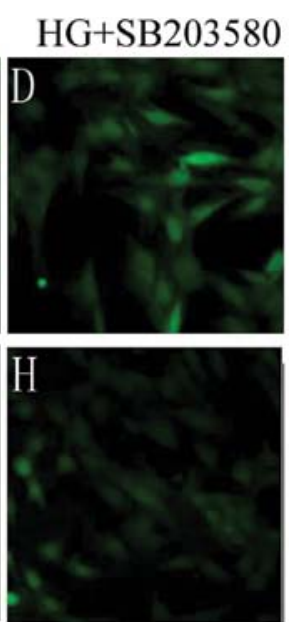

U0126

I

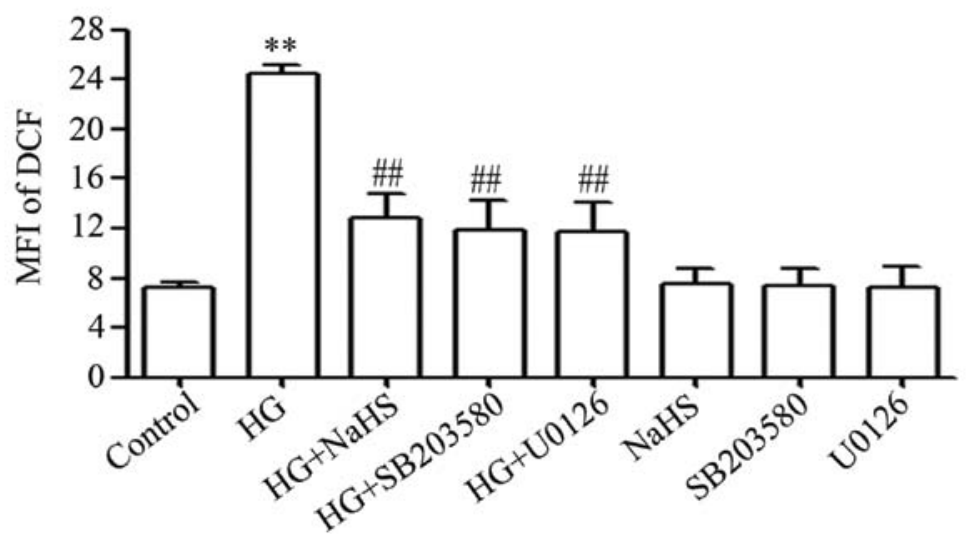

Figure 5. Exogenous hydrogen sulfide $\left(\mathrm{H}_{2} \mathrm{~S}\right)$, p38 mitogen-activated protein kinase (MAPK) inhibitor and extracellular regulated-signal kinase (ERK)1/2, inhibitor attenuate the high glucose $(\mathrm{HG})$-induced overproduction of reactive oxygen species (ROS) in $\mathrm{H} 9 \mathrm{c} 2 \mathrm{cells}$. (A-H) After the H9c2 cells were exposed to the indicated treatments, intracellular ROS generation was examined by DCFH-DA staining followed by photofluorography. (A) Control group; H9c2 cells were (B) treated by $35 \mathrm{mM}$ glucose for $24 \mathrm{~h}$; (C) pre-treated with $400 \mu \mathrm{M}$ NaHS for 30 min prior to exposure to $35 \mathrm{mM}$ glucose for $24 \mathrm{~h}$; (D) pre-treated with $3 \mu \mathrm{M}$ SB203580 for $60 \mathrm{~min}$ followed by exposure to $35 \mathrm{mM}$ glucose for $24 \mathrm{~h}$; (E) pre-treated with $15 \mu \mathrm{M}$ U0126 for 60 min followed by exposure to $35 \mathrm{mM}$ glucose for $24 \mathrm{~h}$; (F) treated with $400 \mu \mathrm{M}$ NaHS for $30 \mathrm{~min}$ followed by $24 \mathrm{~h}$ of culture; (G) treated with $3 \mu \mathrm{M} \mathrm{SB} 203580$ for 60 min followed by $24 \mathrm{~h}$ of culture; (H) treated with $15 \mu \mathrm{M}$ U0126 for 60 min followed by $24 \mathrm{~h}$ of culture; (I) quantitative analysis of mean fluorescence intensity (MFI) of DCF in (A-H) using ImageJ 1.41 o software. Data are shown as the means $\pm \mathrm{SE}(\mathrm{n}=3) .{ }^{* *} \mathrm{P}<0.01$ vs. the control group; ${ }^{\# \#} \mathrm{P}<0.01$ vs. the HG-treated group.

damage are not yet fully understood. Consistent with the data from previous studies $(4,5,8-10)$, our results revealed that the exposure of $\mathrm{H} 9 \mathrm{c} 2$ cardiac cells to $35 \mathrm{mM}(\mathrm{HG})$ induced significant injury, as evidenced by a decrease in cell viability, an increase in the number of apoptotic cells and ROS production, as well as the dissipation of MMP. In order to clarify the correlation between the increased ROS levels and cytotoxicity, the $\mathrm{H} 9 \mathrm{c} 2$ cells were pre-treated with NAC, a scavenger of ROS, prior to exposure to HG. The results of this study demonstrated that NAC pre-treatment markedly inhibited HG-induced cytotoxicity, leading to an increase in cell viability, suggesting the critical role of ROS in HG-elicited cardiomyocyte insults, which is supported by the results of previous studies (5,8-10).

Since the activation of p38 MAPK and ERK1/2 has been shown to contribute to the development of diabetic complications, such as diabetic nephropathy (14) and retinopathy (26), in this study, we first examined the effects of $\mathrm{HG}$ on the phosphorylation of p38 MAPK and ERK1/2 in H9c2 cells. Our results revealed that exposure of the cells to $35 \mathrm{mM}$ glucose markedly enhanced the expression levels of p-p38 MAPK and p-ERK1/2, indicating the activation of p38 MAPK and ERK1/2 by HG.
Similar to our results, p38 MAPK and ERK1/2 are activated in HG-induced human retinal pigmented epithelial cells (26). In addition, the chronic exposure of human mesangial cells to HG activates the p38 MAPK pathway (27). Our data are comparable with those of previous studies $(26,27)$. Based on our findings, as well as those of previous studies $(26,27)$, it can by hypothesized that HG may be an inducer of MAPK pathway activation.

Secondly, we investigated the roles of p38 MAPK and ERK1/2 in HG-induced cardiomyocyte injury. p38 MAPK and ERK1/2 are activated by cellular stress and have been reported to participate in cardiomycyte apoptosis and cardiac pathologies $(28,29)$. The present study demonstrated that the pre-treatment of H9c2 cells with SB203580 (a selective inhibitor of p38 MAPK) markedly ameliorated HG-induced injury (including cytotoxicity, apoptosis, overproduction of ROS and the loss of MMP), as evidenced by an increase in cell viability and a decrease in the number of apoptotic cells and ROS production, as well as the attenuation of the dissipation of MMP. These results suggest that the activation of p38 MAPK contributes to HG-induced cytotoxicity, apoptosis 

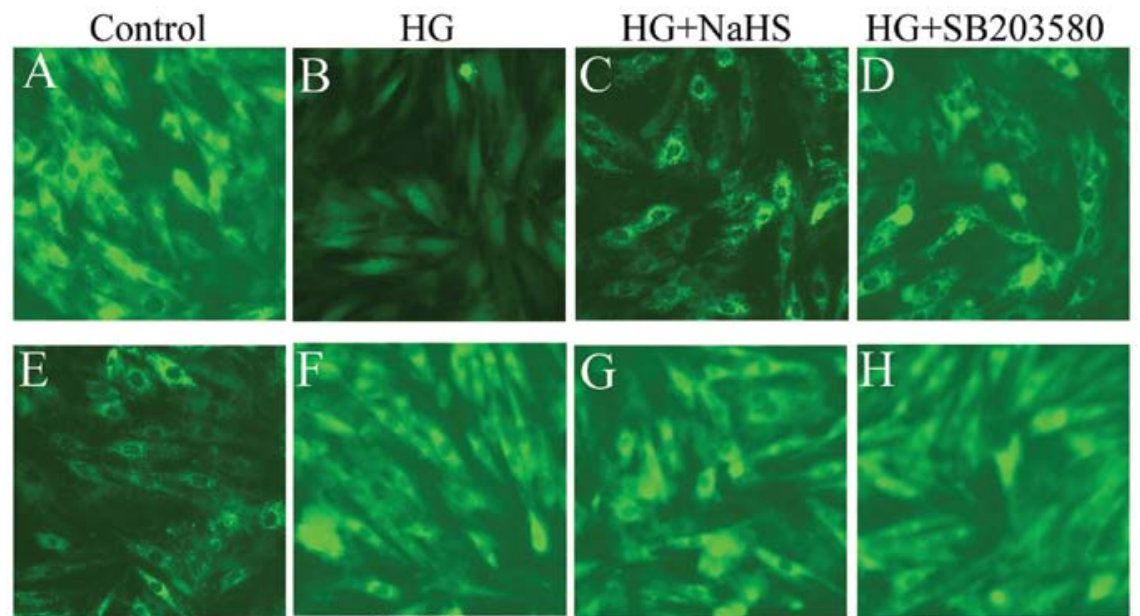

HG+U0126

NaHS

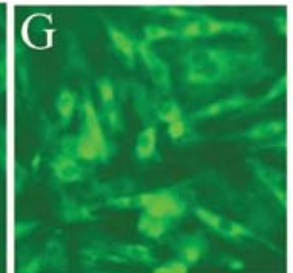

SB203580

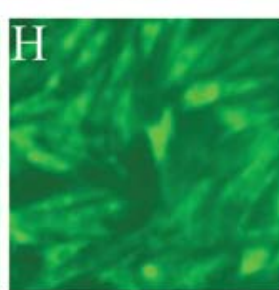

U0126

I

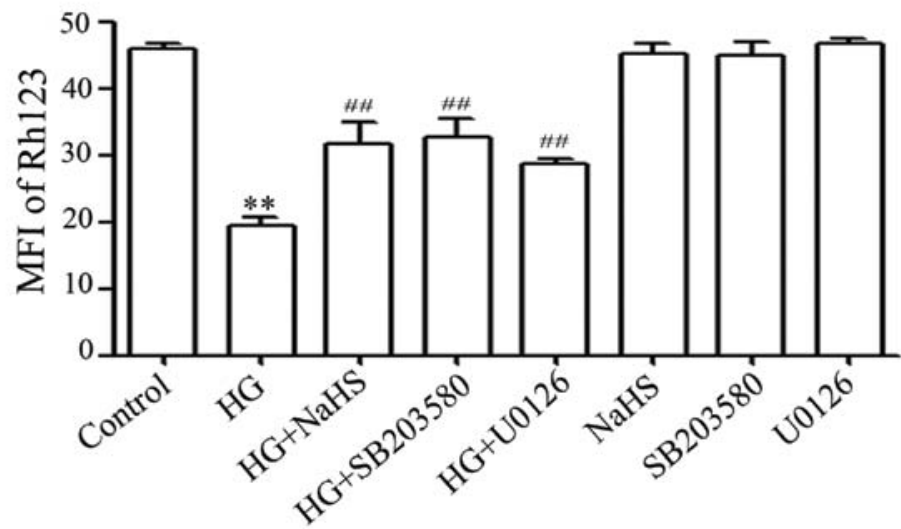

Figure 6. Exogenous hydrogen sulfide $\left(\mathrm{H}_{2} \mathrm{~S}\right)$, p38 mitogen-activated protein kinase (MAPK) inhibitor and extracellular regulated-signal kinase (ERK)1/2 inhibitor block the high glucose (HG)-induced dissipation of mitochondrial membrane potential (MMP) in H9c2 cells. (A-H) After the indicated treatments, MMP was measured by rhodamine 123 (Rh123) staining followed by photofluorography. (A) Control group; H9c2 cells were (B) treated with 35 mM glucose for $24 \mathrm{~h}$; (C) pre-conditioned with $400 \mu \mathrm{M}$ NaHS for 30 min prior to exposure to $35 \mathrm{mM}$ glucose for $24 \mathrm{~h}$; (D) pre-conditioned with $3 \mu \mathrm{M}$ SB203580 for 60 min prior to exposure to $35 \mathrm{mM}$ glucose for $24 \mathrm{~h}$; (E) pre-conditioned with $15 \mu \mathrm{M}$ U0126 for 60 min prior to exposure to $35 \mathrm{mM}$ glucose for $24 \mathrm{~h}$; (F) treated with $400 \mu \mathrm{M}$ NaHS for 30 min followed by $24 \mathrm{~h}$ of culture; (G) treated with $3 \mu \mathrm{M} \mathrm{SB} 203580$ for 60 min followed by $24 \mathrm{~h}$ of culture; (H) treated with $15 \mu \mathrm{M}$ U0126 for $60 \mathrm{~min}$ followed by $24 \mathrm{~h}$ of culture; (I) quantitative analysis of MFI of Rh123 in (A-H) using ImageJ 1.41o software. Data are shown as the means \pm SE (n=6). ${ }^{* *} \mathrm{P}<0.01$ vs. the control group; ${ }^{\# \#} \mathrm{P}<0.01$ vs. the HG-treated group. MFI, mean fluorescence intensity.

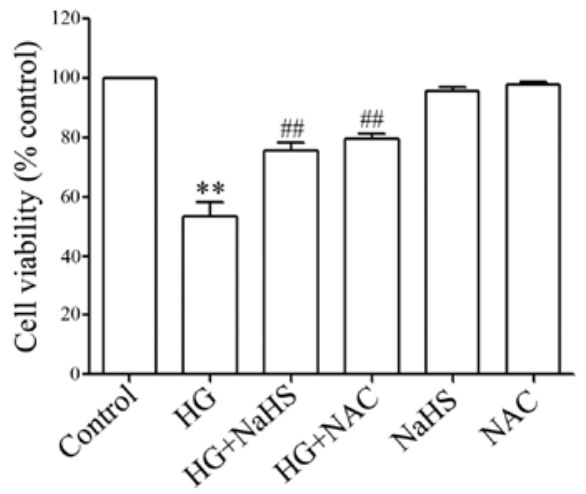

Figure 7. N-acetyl-L-cysteine (NAC) inhibits high glucose (HG)-induced cytotoxicity in $\mathrm{H} 9 \mathrm{c} 2$ cells. $\mathrm{H} 9 \mathrm{c} 2$ cells (pre-treated or not with $1,000 \mu \mathrm{M}$ NAC for $60 \mathrm{~min}$ ) were treated with $35 \mathrm{mM}$ glucose for $24 \mathrm{~h}$. Cell viability was measured using the CCK-8 assay. Data are shown as the means $\pm S E(n=6)$. ${ }^{* *} \mathrm{P}<0.01$ vs. the control group; ${ }^{\# \#} \mathrm{P}<0.01$ vs. the HG-treated group.

and MMP loss, which may be an important mechanism underlying HG-triggered cardiac injury. Our findings support the notion that in the complex signaling events of apoptosis, the activation of p38 MAPK attenuates the mitochondrial function induced by changes in the ratio of pro-apoptotic (Bax) and anti-apoptotic (Bcl-2) members of the mitochondria, causing MMP loss, the release of cytochrome $c$ and the activation of caspases, thus leading to apoptosis (30).

In addition, the role of ERK1/2 in HG-induced injury has gained much attention. The activation of ERK1/2 is stimulated by various stimuli and targets different downstream molecules, and therefore performs different functions. For example, the phosphorylation of ERK1/2/Akt in cardiomyocytes during early reperfusion has been found to serve as a defense mechanism against ischemia (31). Blockage with the ERK1/2-specific inhibitors, PD98059 and U0126, has been shown to inhibit ischemic pre-conditioning-induced cardioprotection (32). U0126 also attenuates the cardioprotective effects induced by fibroblast growth factor-1 (FGF-1) (33). However, the effects of ERK1/2 on cell survival are controversial, as the inhibition of ERK1/2 with U0126 and the downregulation of ERK1/2 using RNA interference has been shown to significantly reduce $\mathrm{H}_{2} \mathrm{O}_{2}$-induced apoptosis in neuronal cell 
lines (PC12 and SH-SY5Y cells) (34). In addition, the activation of the ERK1/2 pathway has been shown to be involved in chemical hypoxia-induced cardiomyocyte insults (23) and STZ-induced cardiac dysfunction (10). In accordance with these studies $(10,23,34)$, in this study, we demonstrate that ERK1/2 activation contributes to HG-induced injury. This is supported by the following findings: i) HG upregulated the expression levels of p-ERK1/2 and ii) U0126 protected H9c2 cells against HG-induced injury, including cytotoxicity, apoptosis, ROS overproduction and the loss of MMP. These findings suggest that stimulating the activation of ERK1/2 may be another key mechanism responsible for HG-induced cardiomyocyte insults.

Importantly, in this study, we demonstrate the potential protective effects of $\mathrm{H}_{2} \mathrm{~S}$ in HG-treated $\mathrm{H} 9 \mathrm{c} 2$ cardiac cells. $\mathrm{H}_{2} \mathrm{~S}$ has been considered as a novel gasomolecule with cardioprotective effects. $\mathrm{H}_{2} \mathrm{~S}$ is produced enzymatically in mammalian species via the action of 3 enzymes in the cysteine biosynthesis pathway: cystathionine- $\gamma$-lyase (CSE), cystathionine- $\beta$-synthase (CBS) and 3-mercaptopyruvate sulfurtransferase (3-MST). Changes in $\mathrm{H}_{2} \mathrm{~S}$ levels in diabetes have attracted attention. There is clear evidence that circulating levels of $\mathrm{H}_{2} \mathrm{~S}$ are reduced in animal models of diabetes (24,35-37). Notably, lower circulating $\mathrm{H}_{2} \mathrm{~S}$ levels have been measured in plasma samples obtained from patients with type 2 diabetes mellitus (T2DM) $(35,38)$. These findings have promoted researchers to explore the protective effects of exogenous $\mathrm{H}_{2} \mathrm{~S}$ against diabetes-induced cardiac injury. Increasing evidence shows that exogenous $\mathrm{H}_{2} \mathrm{~S}$ exerts protective effects against several models of myocardial injury in the setting of type 1 diabetes by preventing apoptosis and oxidative stress $(24,39)$. In db/db mice, $\mathrm{H}_{2} \mathrm{~S}$ therapy in the form of NaHS has been shown to attenuate myocardial ischemia-reperfusion injury (9). In agreement with these studies $(9,24,39)$, we found that exogenous $\mathrm{H}_{2} \mathrm{~S}$ exerted multiple protective effects, including anticytotoxic, anti-apoptotic and antioxidant effects, as well as mitochondrial protective effects (alleviating the loss of MMP), against HG-induced injury in H9c2 cells. One of the mechanisms underlying these protective effects may be associated the antioxidant effects of $\mathrm{H}_{2} \mathrm{~S}$ (lowering ROS production), as NAC, a ROS scavenger, exerted protective effects similar to those of $\mathrm{H}_{2} \mathrm{~S}$ against $\mathrm{HG}$-induced cytotoxicity.

Since we have previously demonstrated the inhibitory effects of exogenous $\mathrm{H}_{2} \mathrm{~S}$ on the chemical hypoxia-induced activation of $\mathrm{p} 38$ MAPK and ERK1/2 in PC12 cells (22) and the activation of ERK1/2 in H9c2 cells (23), in this study, we explored the modulatory effects of exogenous $\mathrm{H}_{2} \mathrm{~S}$ on the HG-stimulated activation of p38 MAPK and ERK1/2 in $\mathrm{H} 9 \mathrm{c} 2$ cells. We found that pre-treatment of the H9c2 cells with NaHS attenuated not only the expression level of p-p38 MAPK, but also that of p-ERK1/2 induced by HG in $\mathrm{H} 9 \mathrm{c} 2$ cells, revealing that exogenous $\mathrm{H}_{2} \mathrm{~S}$ inhibits the HG-induced activation of p38 MAPK and ERK1/2, which may be one of important mechanisms responsible for the cardioprotective effects of exogenous $\mathrm{H}_{2} \mathrm{~S}$ against $\mathrm{HG}$-induced injury in $\mathrm{H} 9 \mathrm{c} 2$ cells. The involvement of hte inhibition of the p38 MAPK pathway in the cytoprotective effects of exogenous $\mathrm{H}_{2} \mathrm{~S}$ has also been reported by other studies. Hu et al indicated that $\mathrm{H}_{2} \mathrm{~S}$ suppresses LPS-induced inflammation by inhibiting p38 MAPK in microglia (40) and that $\mathrm{H}_{2} \mathrm{~S}$ protects SH-SY5Y cells against rotenone-induced apoptosis through the suppression of p38 MAPK activation (41). Additionally, exogenous $\mathrm{H}_{2} \mathrm{~S}$ reduces doxorubicin-induced cardiotoxicity by inhibiting the activation of the p38 MAPK pathway (29). Our results, as well as those from previous studies $(22,29,40,41)$ suggest that exogenous $\mathrm{H}_{2} \mathrm{~S}$ may be a potential inhibitor of $\mathrm{p} 38$ MAPK.

However, reports on the effects of $\mathrm{H}_{2} \mathrm{~S}$ on the activation of ERK1/2 are controversial. The ERK1/2 activation has been shown to be increased $(42-46)$, decreased $(22,23,29,47-49)$ or unaltered $(50,51)$ following exposure to $\mathrm{H}_{2} \mathrm{~S}$. In the present study, we provide clear evidence that the activation of ERK1/2 contributes to HG-induced injury in $\mathrm{H} 9 \mathrm{c} 2$ cells and that exogenous $\mathrm{H}_{2} \mathrm{~S}$ protects $\mathrm{H} 9 \mathrm{c} 2$ cells against HG-induced injury by inhibiting ERK1/2 activation, which is supported by our previous study [Dong et al (23)]. Although the mechanisms through which ERK1/2 induces either cell death or survival and the reasons for the differential effects induced by exogenous $\mathrm{H}_{2} \mathrm{~S}$ on the activation of ERK1/2 are unclear, it is generally accepted that the duration and magnitude of ERK1/2 activation may be an important factor in determining cell survival or apoptosis (52). In addition, exploring the interaction between ERK1/2 and survival or apoptotic regulators may provide important information on the mechanisms underlying the differential effects of exogenous $\mathrm{H}_{2} \mathrm{~S}$ on ERK1/2 activation.

In conclusion, to our knowledge, the findings of present study demonstrate for the first time that exogenous $\mathrm{H}_{2} \mathrm{~S}$ protects against HG-induced injury by attenuating the activation of p38 MAPK and ERK1/2 in H9c2 cardiac cells. Our results also provide important evidence that the activation of p38 MAPK and ERK1/2 is involved in HG-induced multiple cardiomyocyte injury, including cytotoxicity, apoptosis, ROS overproduction and the dissipation of MMP. These findings may provide a rationale for designing effective therapeutic strategies for the treatment of heart disease in the setting of diabetes.

\section{Acknowledgements}

The present study was supported by grants from the Science and Technology Planning Project of Guangdong of China (2010B080701035, 2010B080701105 and 2012B031800358) and the National Natural Science Foundation of China (H0208).

\section{References}

1. Grundy SM, Benjamin IJ, Burke GL, et al: Diabetes and cardiovascular disease: a statement for healthcare professionals from the American Heart Association. Circulation 100: 1134-1146, 1999.

2. Cai L and Kang YJ: Oxidative stress and diabetic cardiomyopathy: a brief review. Cardiovasc Toxicol 1: 181-193, 2001.

3. Francis GS: Diabetic cardiomyopathy: fact or fiction? Heart 85 : 247-248, 2001.

4. Rodrigues B, Cam MC and McNeill JH: Metabolic disturbances in diabetic cardiomyopathy. Mol Cell Biochem 180: 53-57, 1998.

5. Privratsky JR, Wold LE, Sowers JR, Quinn MT and Ren J: AT1 blockade prevents glucose-induced cardiac dysfunction in ventricular myocytes: role of the AT1 receptor and NADPH oxidase. Hypertension 42: 206-212, 2003.

6. Ren J and Davidoff AJ: Diabetes rapidly induces contractile dysfunctions in isolated ventricular myocytes. Am J Physiol 272: H148-H158, 1997.

7. Rahimi R, Nikfar S, Larijani B and Abdollahi M: A review on the role of antioxidants in the management of diabetes and its complications. Biomed Pharmacother 59: 365-373, 2005. 
8. Cai $\mathrm{H}$ and Harrison DG: Endothelial dysfunction in cardiovascular diseases: the role of oxidant stress. Circ Res 87: 840-844, 2000.

9. Peake BF, Nicholson CK, Lambert JP, et al: Hydrogen sulfide preconditions the $\mathrm{db} / \mathrm{db}$ diabetic mouse heart against ischemia-reperfusion injury by activating Nrf2 signaling in an Erk-dependent manner. Am J Physiol Heart Circ Physiol 304: H1215-H1224, 2013.

10. Soetikno V, Sari FR, Sukumaran V, et al: Curcumin prevents diabetic cardiomyopathy in streptozotocin-induced diabetic rats: possible involvement of PKC-MAPK signaling pathway. Eur J Pharm Sci 47: 604-614, 2012.

11. Evans JL, Goldfine ID, Maddux BA and Grodsky GM: Oxidative stress and stress-activated signaling pathways: a unifying hypothesis of type 2 diabetes. Endocr Rev 23: 599-622, 2002.

12. Igarashi $\mathrm{M}$, Wakasaki $\mathrm{H}$, Takahara $\mathrm{N}$, et al: Glucose or diabetes activates p38 mitogen-activated protein kinase via different pathways. J Clin Invest 103: 185-195, 1999.

13. Yan J, Young ME, Cui L, Lopaschuk GD, Liao R and Tian R Increased glucose uptake and oxidation in mouse hearts prevent high fatty acid oxidation but cause cardiac dysfunction in diet-induced obesity. Circulation 119: 2818-2828, 2009.

14. Fang S, Jin Y,Zheng H, et al: High glucose condition upregulated Txnip expression level in rat mesangial cells through ROS/MEK/ MAPK pathway. Mol Cell Biochem 347: 175-182, 2011.

15. Łowicka E and Bełtowski J: Hydrogen sulfide $\left(\mathrm{H}_{2} \mathrm{~S}\right)$ - the third gas of interest for pharmacologists. Pharmacol Rep 59: 4-24, 2007.

16. Moore PK, Bhatia M and Moochhala S: Hydrogen sulfide: from the smell of the past to the mediator of the future? Trends Pharmacol Sci 24: 609-611, 2003.

17. Geng B, Chang L, Pan C, et al: Endogenous hydrogen sulfide regulation of myocardial injury induced by isoproterenol. Biochem Biophys Res Commun 318: 756-763, 2004.

18. Calvert JW, Jha S, Gundewar S, et al: Hydrogen sulfide mediates cardioprotection through Nrf2 signaling. Circ Res 105: 365-374, 2009.

19. Chen SL, Yang CT, Yang ZL, et al: Hydrogen sulphide protects H9c2 cells against chemical hypoxia-induced injury. Clin Exp Pharmacol Physiol 37: 316-321, 2010.

20. Yang Z, Yang C,Xiao L, et al: Novel insights into the role of HSP90 in cytoprotection of $\mathrm{H}_{2} \mathrm{~S}$ against chemical hypoxia-induced injury in H9c2 cardiac myocytes. Int J Mol Med 28: 397-403, 2011.

21. Nicholson CK and Calvert JW: Hydrogen sulfide and ischemia-reperfusion injury. Pharmacol Res 62: 289-297, 2010.

22. Lan A, Liao X, Mo L, et al: Hydrogen sulfide protects against chemical hypoxia-induced injury by inhibiting ROS-activated ERK1/2 and p38MAPK signaling pathways in PC12 cells. PLoS One 6: e25921, 2011.

23. Dong XB, Yang CT, Zheng DD, et al: Inhibition of ROS-activated ERK1/2 pathway contributes to the protection of $\mathrm{H}_{2} \mathrm{~S}$ against chemical hypoxia-induced injury in $\mathrm{H} 9 \mathrm{c} 2$ cells. Mol Cell Biochem 362: 149-157, 2012.

24. Suzuki K, Olah G, Modis K, et al: Hydrogen sulfide replacement therapy protects the vascular endothelium in hyperglycemia by preserving mitochondrial function. Proc Natl Acad Sci USA 108 13829-13834, 2011

25. Malhotra A, Vashistha H, Yadav VS, et al: Inhibition of p66ShcA redox activity in cardiac muscle cells attenuates hyperglycemiainduced oxidative stress and apoptosis. Am J Physiol Heart Circ Physiol 296: H380-H388, 2009.

26. Yuan Z, Feng W, Hong J, Zheng Q, Shuai J and Ge Y: p38MAPK and ERK promote nitric oxide production in cultured human retinal pigmented epithelial cells induced by high concentration glucose. Nitric Oxide 20: 9-15, 2009.

27. Wilmer WA, Dixon CL and Hebert C: Chronic exposure of human mesangial cells to high glucose environments activates the p38 MAPK pathway. Kidney Int 60: 858-871, 2001.

28. Sugden PH and Clerk A: 'Stress-responsive' mitogen-activated protein kinases (c-Jun $\mathrm{N}$-terminal kinases and p38 mitogen-activated protein kinases) in the myocardium. Circ Res 83: 345-352, 1998.

29. Guo R, Lin J, Xu W, et al: Hydrogen sulfide attenuates doxorubicin-induced cardiotoxicity by inhibition of the p38 MAPK pathway in H9c2 cells. Int J Mol Med 31: 644-650, 2013.

30. Yang J, Liu X, Bhalla K, et al: Prevention of apoptosis by Bcl-2: release of cytochrome c from mitochondria blocked. Science 275: 1129-1132, 1997
31. YueTL,WangC,GuJL,etal:Inhibitionofextracellularsignal-regulated kinase enhances Ischemia/Reoxygenation-induced apoptosis in cultured cardiac myocytes and exaggerates reperfusion injury in isolated perfused heart. Circ Res 86: 692-699, 2000.

32. Strohm C, Barancik T, Brühl ML, Kilian SA and Schaper W: Inhibition of the ER-kinase cascade by PD98059 and UO126 counteracts ischemic preconditioning in pig myocardium. J Cardiovasc Pharmacol 36: 218-229, 2000

33. Buehler A, Martire A, Strohm C, et al: Angiogenesis-independent cardioprotection in FGF-1 transgenic mice. Cardiovasc Res 55: 768-777, 2002

34. Chen L, Liu L, Yin J, Luo Y and Huang S: Hydrogen peroxide-induced neuronal apoptosis is associated with inhibition of protein phosphatase $2 \mathrm{~A}$ and 5 , leading to activation of MAPK pathway. Int J Biochem Cell Biol 41: 1284-1295, 2009.

35. Jain SK, Bull R, Rains JL, et al: Low levels of hydrogen sulfide in the blood of diabetes patients and streptozotocin-treated rats causes vascular inflammation? Antioxid Redox Signal 12: 1333-1337, 2010

36. Yusuf M, Kwong Huat BT, Hsu A, Whiteman M, Bhatia M and Moore PK: Streptozotocin-induced diabetes in the rat is associated with enhanced tissue hydrogen sulfide biosynthesis. Biochem Biophys Res Commun 333: 1146-1152, 2005.

37. Ahmad FU, Sattar MA, Rathore HA, et al: Exogenous hydrogen sulfide $\left(\mathrm{H}_{2} \mathrm{~S}\right)$ reduces blood pressure and prevents the progression of diabetic nephropathy in spontaneously hypertensive rats. Ren Fail 34: 203-210, 2012

38. Whiteman M, Gooding KM, Whatmore JL, et al: Adiposity is a major determinant of plasma levels of the novel vasodilator hydrogen sulphide. Diabetologia 53: 1722-1726, 2010.

39. Gao Y, Yao X, Zhang Y, et al: The protective role of hydrogen sulfide in myocardial ischemia-reperfusion-induced injury in diabetic rats. Int J Cardiol 152: 177-183, 2011.

40. Hu LF, Wong PT, Moore PK and Bian JS: Hydrogen sulfide attenuates lipopolysaccharide-induced inflammation by inhibition of p38 mitogen-activated protein kinase in microglia. J Neurochem 100: 1121-1128, 2007.

41. Hu LF, Lu M, Wu ZY, Wong PT and Bian JS: Hydrogen sulfide inhibits rotenone-induced apoptosis via preservation of mitochondrial function. Mol Pharmacol 75: 27-34, 2009.

42. Adhikari S and Bhatia $\mathrm{M}: \mathrm{H}_{2} \mathrm{~S}$-induced pancreatic acinar cell apoptosis is mediated via JNK and p38 MAP kinase. J Cell Mol Med 12: 1374-1383, 2008.

43. Zhi L, Ang AD, Zhang H, Moore PK and Bhatia M: Hydrogen sulfide induces the synthesis of proinflammatory cytokines in human monocyte cell line U937 via the ERK-NF-kappaB pathway. J Leukoc Biol 81: 1322-1332, 2007.

44. Mukherjee S, Lekli I, Goswami S and Das DK: Freshly crushed garlic is a superior cardioprotective agent than processed garlic. J Agric Food Chem 57: 7137-7144, 2009.

45. Hu Y, Chen X, Pan TT, et al: Cardioprotection induced by hydrogen sulfide preconditioning involves activation of ERK and PI3K/Akt pathways. Pflugers Arch 455: 607-616, 2008.

46. Yang G, Wu L, Bryan S, Khaper N, Mani S and Wang R: Cystathionine gamma-lyase deficiency and overproliferation of smooth muscle cells. Cardiovasc Res 86: 487-495, 2010.

47. Yang G, Yang W, Wu L and Wang R: $\mathrm{H}_{2}$ S, endoplasmic reticulum stress, and apoptosis of insulin-secreting beta cells. J Biol Chem 282: 16567-16576, 2007

48. $\mathrm{Lu} \mathrm{M}, \mathrm{Hu} \mathrm{LF}, \mathrm{Hu} \mathrm{G}$ and Bian JS: Hydrogen sulfide protects astrocytes against $\mathrm{H}(2) \mathrm{O}(2)$-induced neural injury via enhancing glutamate uptake. Free Radic Biol Med 45: 1705-1713, 2008.

49. Kloesch B, Liszt $\mathrm{M}$ and Broell $\mathrm{J}: \mathrm{H}_{2} \mathrm{~S}$ transiently blocks IL-6 expression in rheumatoid arthritic fibroblast-like synoviocytes and deactivates p44/42 mitogen-activated protein kinase. Cell Biol Int 34: 477-484, 2010.

50. Cai WJ, Wang MJ, Moore PK, Jin HM, Yao T and Zhu YC: The novel proangiogenic effect of hydrogen sulfide is dependent on Akt phosphorylation. Cardiovase Res 76: 29-40, 2007.

51. Bliksøen M, Kaljusto ML, Vaage J and Stensløkken KO: Effects of hydrogen sulphide on ischaemia-reperfusion injury and ischaemic preconditioning in the isolated, perfused rat heart. Eur J Cardiothorac Surg 34: 344-349, 2008.

52. Marshall CJ: Specificity of receptor tyrosine kinase signaling: transient versus sustained extracellular signal-regulated kinase activation. Cell 80: 179-185, 1995. 